\title{
INFLUENCE OF FINE ADDITIVES AND SURFACTANTS ON THE STRENGTH AND PERMEABILITY DEGREE OF CONCRETE
}

\author{
Oksana Shkromada \\ Department of Therapy, Pharmacology, Clinical Diagnostics and Chemistry ${ }^{1}$ \\ oshkromada@gmail.com \\ Andriy Paliy \\ Department of Technical Systems and Animal Husbandry Technologies \\ Kharkiv Petro Vasylenko National Technical University of Agriculture \\ 44 Alchevskih str., Kharkiv, Ukraine, 61002 \\ paliy.andriy@ukr.net \\ Oksana Yurchenko \\ Department of Construction Production ${ }^{1}$ \\ kosareva_82@mail.ua \\ Nadiia Khobot \\ Department of Architecture and Engineering Studies ${ }^{1}$ \\ 14.khobot@gmail.com \\ Alina Pikhtirova \\ Department of Public Health \\ Sumy State University \\ 2 Rymskogo-Korsakova str., Sumy, Ukraine, 40007 \\ alinca.sumy@gmail.com \\ Ivan Vysochin \\ Department of Architecture and Engineering Studies ${ }^{1}$ \\ via1946@ukr.net \\ Ganna Fedorenko \\ Department of Automation of Production Processes \\ Kharkiv National University of Civil Engineering and Architecture \\ 40 Sumska str., Kharkiv, Ukraine, 61001 \\ a_gunchenko@ukr.net \\ Anatoliy Paliy \\ Laboratory of Veterinary Sanitation and Parasitology \\ National Scientific Center "Institute of Experimental and Clinical Veterinary Medicine» \\ 83 Pushkinska str., Kharkiv, Ukraine, 61023 \\ paliy.dok@gmail.com \\ ${ }^{1}$ Sumy National Agrarian University \\ 160 Herasym Kondratiev str., Sumy, Ukraine, 40021
}

\footnotetext{
Abstract

The results of studies to determine the effect of titanium dioxide nanoparticles (nanoTiO ${ }_{2}$ ), finely dispersed anatase crystalline titanium dioxide ( $a$ atazTiO ${ }_{2}$ ) and surface-active substances (surfactants) on the compressive strength, degree of permeability and thermal stability of concrete samples are presented. Adding particles of nanotitanium, anatase titanium and surfactants up to $2 \%$ to cement accelerates the hydration process and increases the strength of concrete, and also has a strong effect on its microstructure.

As a result of the studies, it is experimentally proved that the compressive strength of concrete increases with the addition of titanium dioxide $\left(\right.$ nanoTiO ${ }_{2}$ ) nanoparticles by $23.2 \%$, finely dispersed anatase crystalline titanium dioxide $\left(\operatorname{anatazTiO}_{2}\right)$ by $21.7 \%$ to $5 \%$ concentration by weight.
} 
In addition, the introduction of these additives reduces the permeability of concrete. This is due to a decrease in the absorption of concrete by water with the addition of nanotitanium and anatase titanium. The introduction of additives from $1 \%$ to $5 \%$ by weight in concrete reduces the depth of chloride penetration by 10-15 times, compared with the control.

The use of temperature-programmed desorption mass spectrometry (TPD-MS) method has shown that an increase in the percentage of $\mathrm{TiO}_{2}$ nanoparticles to $5 \%$ in concrete mixtures correlates with an increase in microporosity and dispersion level of these mixtures, which causes a shift in the peaks of intense gas evolution from the samples when heated to the side low temperatures (for example, carbon dioxide $\mathrm{CO}_{2}$ ).

The resulting concrete samples are planned to be used for the manufacture of floors in livestock buildings. The injected additives are selected because they are not toxic substances and, in contact with the biological environment of livestock buildings (urine, feces), will not react with them.

Keywords: concrete, nanotitanium, anatase titanium, surfactants, compressive strength, permeability, thermal properties.

DOI: $10.21303 / 2461-4262.2020 .001178$

\section{Introduction}

The creation of materials with enhanced physical and mechanical characteristics is due to the improvement and development of the technology for the construction of buildings and structures.

Concrete coatings are used very often in livestock buildings, for road surfaces. They are subject to special requirements for strength and permeability.

Among semiconductors with photocatalytic properties based on oxides and sulfites, one can distinguish titanium dioxide $\left(\mathrm{TiO}_{2}\right)$, zinc oxide $(\mathrm{ZnO})$, tungsten oxide $\left(\mathrm{WO}_{3}\right)$. Nevertheless, titanium dioxide is taken due to its high photocatalytic activity, chemical stability, and availability. These abilities have only recently been used for concrete and products from it. In addition to photocatalytic activity, its mechanical properties and durability are important. Studies have been conducted of concrete containing $\mathrm{TiO}_{2}$ nanoparticles for paving, which describe the fatigue characteristics of concrete and its susceptibility to stress. The researchers [1] show that the introduction of $\mathrm{TiO}_{2}$ nanoparticles into the concrete mixture increases the degree of abrasion resistance.

In our work, part of the cement was replaced by nanoparticles of titanium dioxide $\left(\right.$ nanoTiO ${ }_{2}$ ), finely divided titanium dioxide in anatase crystalline form (anatazTiO ${ }_{2}$ ) and surfactant, which made it possible to increase the strength and permeability of concrete. As nanocrystalline filler, titanium dioxide $\left(\mathrm{TiO}_{2}\right)$ with a particle size of less than 0.5 microns and a fine crystalline filler titanium anatase with a particle size of 3-5 microns are used. Nanomaterials have a greater relationship between surface area and volume than other similar particles in a larger size, which makes nanomaterials more reactive $[2,3]$.

Scientific interest is due to new potential applications of particles of the order of nanometers. Nanomaterials have a greater relationship between surface area and volume than other similar larger particles, which makes them more reactive. It is usually expected that if the volume concentration of the solid is kept constant, for specific workability, replacing the cement with fine powder will increase the need for water due to an increase in surface area. This is more observed when nanoparticles are introduced into mixed (multicomponent) concrete [4].

Also, a surfactant is introduced into the concrete mixture. Alkyl trimethylamine chloride (surfactant) belongs to the group of disinfectants containing a quaternary ammonium salt, nonionic surfactant, lower alcohol complexon. The tool is used as a substitute for cyanide compounds in electrolytes, in humane medicine for the disinfection of surgical instruments, equipment, drying cabinets, rooms. Due to their ability to form a film around concrete particles, they are also a good filler to reduce pores in concrete and particle binding $[5,6]$.

Surfactants can enhance air entrainment with cement paste (air-entraining agents) with rapid mixing of the cement slurry, or they can be used to create pre-formed aqueous foam, and are later incorporated into the cement slurry. In both processes, surfactants remain in the cement paste and can thus affect the rheological properties and aging of the cement matrix. In addition to cement foams, surfactants can be used as air entrainment agents in frost-resistant concrete and as additives that reduce shrinkage [7]. 
The tests of the samples for the permeability of chloride ions showed that the introduction of nanotitanium $\mathrm{TiO}_{2}$, anatase titanium and a surfactant into concrete leads to a decrease in this indicator, compared to control samples. Also in the work, concrete samples with a content of 1 and $2 \%$ concentration of a surfactant showed an increase in compression density by $18,9 \%$ and $21.7 \%$, respectively, compared with control samples.

The addition of microcrystalline fillers can also affect the dimensional stability of the cement mixture by increasing the shrinkage of the cement material. The particle size of the filler can be optimally selected so that the filler can increase the hydration reaction, but not significantly affect the dimensional stability of the cement system. The addition of small non-reactive filler to the cement modifies the hydration reaction mainly due to dilution, modification of particle size distribution, and heterogeneous nucleation $[8,9]$.

The binder phase of the cement mixture is formed during the reaction (hydration) of the Portland cement clinker with water. The main component of concrete is cement, which consists of $60 \%$ calcium oxide $(\mathrm{CaO})$, clay and various oxides and impurities. When water mixes with cement, a series of complex reactions begin. In traditional concrete mixtures, the main components of strength are calcium silicates, which react with water to form a calcium silicate hydrate gel [10]. There is not enough data on how $\mathrm{TiO}_{2}$ particles affect the level of carbonation in concrete, which was shown in this paper.

The use of temperature-programmed desorption mass spectrometry (TPD-MS) in work made it possible to obtain data on the effects of nanotitanium, anatase titanium, and surfactants on the thermal properties of concrete samples. The introduction of additives into concrete mixtures gave the result of a decrease in the temperature of maximum heating of the experimental samples to $520-530{ }^{\circ} \mathrm{C}$ and the prevalence of endothermic processes over exothermic ones [11].

It is also experimentally proved that during the heating of concrete, evaporation of water and other hydrated substances occurs, which leads to weight loss of the samples [12].

The priority in construction is to increase the strength of concrete. Thus, the main direction in the development of the physicomechanical characteristics of concrete and concrete mixtures is the introduction of a small amount of finely dispersed additives into the concrete mixture, which can increase the compressive strength of concrete. Such additives can serve as surface-active substances that affect the mobility of the concrete mixture and organic compounds.

\section{Materials and Methods}

The aim of research is studying the effect of additives based on titanium dioxide nanoparticles $\left(\right.$ nanoTiO ${ }_{2}$ ), finely dispersed anatase crystalline titanium dioxide (anatazTiO $)$, surfactants (alkyl trimethylamine chloride) on strength, permeability and thermal properties.

To achieve this aim, the following objectives are solved:

- to determine the physico-mechanical properties of concrete samples with various additives (compressive strength and permeability);

- to study the effect of additives based on nanoparticles of titanium dioxide (nanoTiO $)_{2}$, finely divided titanium dioxide in anatase crystalline form (anatazTiO ${ }_{2}$ ), surfactants on the thermal properties of concrete samples.

The studies were conducted in the laboratory of architecture and engineering surveys of Sumy National Agrarian University (Ukraine) during 2019. For the experiment, Portland cement M 400 Kryvyi Rih (Ukraine); river sand and crushed stone Sumy, Ukraine was used. Nanotitanium, titanium anatase PJSC "Sumykhimprom" (Ukraine), and a surfactant, alkyl trimethylamine chloride, were used as an additive to concrete.

Concrete mixtures were prepared with different contents of titanium dioxide nanoparticles $\mathrm{TiO}_{2}$ less than 0.5 microns; with a particle size of 3-5 microns - finely divided titanium dioxide in anatase crystalline form. Surfactants were introduced into the concrete mixture in 1 and $2 \%$ concentration. A concrete mixture was prepared with replacement of cement with $\mathrm{TiO}_{2}$ particles from 1 to $5 \mathrm{wt}$. $\%$. The content of all mixtures is $500 \mathrm{~kg} / \mathrm{m}^{3}$. The proportions of the mixtures are presented in Table 1. 
Table 1

Proportional ratios of concrete mix

\begin{tabular}{cccc}
\hline $\mathbf{T i O}_{2}(\%)$ & \multicolumn{2}{c}{ Amount $\left(\mathbf{k g} / \mathbf{m}^{3}\right)$} & $\mathbf{T i O}_{2}$ \\
\cline { 2 - 4 } & Cement & 0 \\
1 & 500 & 5 \\
2 & 495 & 10 \\
5 & 490 & 25
\end{tabular}

In the laboratory, the investigated concrete samples were manufactured with dimensions of $70 \times 70 \times 70 \mathrm{~mm}^{3}$, the hardening exposure was 7,28 and 90 days. The physicomechanical properties of concrete studies of compressive strength were determined according to the generally accepted method [13].

The result of chloride ion penetration into concrete samples was evaluated by immersing concrete cubes from all sides, except for one in a $3 \% \mathrm{NaCl}$ solution for 28 days. After that, the samples were destroyed and silver was sprayed with $0.1 \%$ nitrate solution to determine the depth of chloride penetration [14]. These depths were defined as points in samples where free chlorides exceeded $0.15 \%$ by weight of cement. Chlorides reacted with a solution of silver nitrate $\left(\mathrm{AgNO}_{3}\right)$ $0.1 \%$ to form a white precipitate of silver chloride $(\mathrm{AgCl})$. The absence or limited presence of free chloride was expressed by a brown precipitate of silver oxide ( $\mathrm{AgO})$, resulting from the reaction of a solution of $\mathrm{AgNO}_{3}$ and hydroxides in concrete samples.

To study the thermal properties of concrete samples, let's use a thermal programmed mass spectrometry (TPD-MS) unit, which consists of a high-temperature furnace and a MX-7304 gas mass spectrometer (SELMI OJSC, Sumy, Ukraine). Samples weighing $3 \mathrm{mg}$ were taken for the experiment. The technical details of the experiment are presented in detail in [15].

Peaks of temperature, the rate of heating of the sample, weight loss, and ions with molecular masses $(\mathrm{m} / \mathrm{z})$ isolated in this case were recorded: 2 - hydrogen; 16 - oxygen; 18 - water; 28 - carbon monoxide $(\mathrm{CO})$ and 44 - carbon dioxide $\left(\mathrm{CO}_{2}\right)$.

Fig. 5-7 show the curves of the result of thermal analysis for experimental concrete samples with the addition of titanium dioxide nanoparticles $\mathrm{TiO}_{2}$ less than $0.5 \mu \mathrm{m}$; with a particle size of 3-5 microns - finely divided titanium dioxide in anatase crystalline form. Surfactants were introduced into the concrete mixture in 1 and $2 \%$ concentration. On the temperature curves, an endothermic process of the loss of water molecules at a temperature of from $300{ }^{\circ} \mathrm{C}$ to $420{ }^{\circ} \mathrm{C}$ is observed. At temperatures from $420^{\circ} \mathrm{C}$ to $720^{\circ} \mathrm{C}$, the process is endothermic due to the dissociation of carbonates.

\section{Results} concrete

3. 1. Research results of the compressive strength and penetration of chloride into

Table 2 shows the results of testing the compressive strength of concrete samples on the 7th, 28th and 90th day of hardening. The data obtained show that the compressive strength increases with the addition of additives in $1 \%$ concentration of titanium dioxide nanoparticles by $18.4 \%$; finely divided titanium dioxide in anatase crystalline form - by $16.5 \%$, compared with the control.

When the admixture is increased to $5 \%$, the strength of concrete samples decreases, however, the performance is still higher in comparison with the control concrete mix without additives (Table 2).

The strength of samples containing $2 \%$ nanoparticles of titanium dioxide $($ nanoTiO $)$ increases by $23.2 \%$, finely divided titanium dioxide in anatase crystalline form (anatazTiO ${ }_{2}$ ) - by $21.7 \%$, respectively.

Probably, a decrease in the strength of $5 \%$ concrete is associated with an excess of the amount of titanium particles necessary to fill the pores of the concrete. Also, a larger percent- 
age of titanium dioxide nanoparticles than $2.0 \%$ reduces the compressive strength due to a decrease in hydrated lime content. And this leads to a lack of strength. As a result of the high reactivity of titanium dioxide nanoparticles, there is a rapid consumption of crystalline calcium hydroxide, which is formed during the hydration of Portland cement in the early stages of hardening. As a result, cement hydration is accelerated, and large volumes of reaction products are formed.

Table 2

Assessment of compressive strength of concrete samples

\begin{tabular}{ccccc}
\hline \multirow{2}{*}{ Samples } & \% & \multicolumn{3}{c}{ Compressive strength (MPa) } \\
\cline { 3 - 5 } & 0 & $\mathbf{7}$ days & $\mathbf{2 8}$ days & $\mathbf{9 0}$ days \\
\hline $\mathrm{TiO}_{2}$ & 1 & 16,0 & 42,6 & 61,2 \\
nanotitanium & 2 & 20,5 & 50,2 & 72,5 \\
& 5 & 23,6 & 56,4 & 75,4 \\
$\mathrm{TiO}_{2}$ & 1 & 24,5 & 57,3 & 70,8 \\
Titanium anatase & 2 & 22,3 & 49,5 & 71,3 \\
& 5 & 24,5 & 53,6 & 74,5 \\
Surfactant & 1 & 21,5 & 52,9 & 69,6 \\
& 2 & 18,5 & 43,5 & 72,8
\end{tabular}

Concrete samples containing 1 and $2 \%$ surfactant concentration show an increase in compression density by $18.9 \%$ and $21.7 \%$, respectively, compared to control samples. This process occurs due to a decrease in the volume of large pores.

To confirm the improvement of the strength properties of concrete, an experiment is conducted on the permeability of concrete with various additives. The depths of chloride penetration into the samples are calculated after 28 days of immersion in $5 \% \mathrm{NaCl}$ solution (Fig. 1). The results show that in the control samples of concrete there is enhanced chloride penetration, compared with the experimental ones.

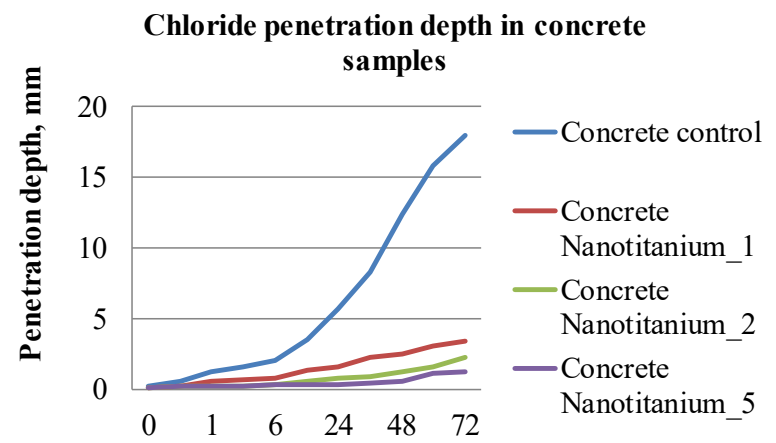

Fig. 1. The penetration depth of chlorides in concrete samples, with an exposure of 0-72 hours

For control mixtures of concrete without additives, the penetration depth is $17.9 \%$. When a nanodispersed additive of titanium dioxide is introduced into concrete from $1 \%$ to $5 \%$, the chloride penetration depth decreases to $3.0 \mathrm{~mm}$, respectively.

The addition of anatase titanium to the concrete mixture, depending on the concentration, changes the degree of chloride penetration at various exposures (Fig. 2).

The addition of a small-crystalline admixture of titanium anatase to concrete in the range of $1 \%$ to $5 \%$, the absorption depth of a $3 \% \mathrm{NaCl}$ solution stops at around $2.6-4.2 \mathrm{~mm}$, respectively. So, thanks to additives, the formed structure has discontinuous pores and significantly reduces the penetration of chlorides into the samples. 


\section{Chloride penetration depth in concrete samples}

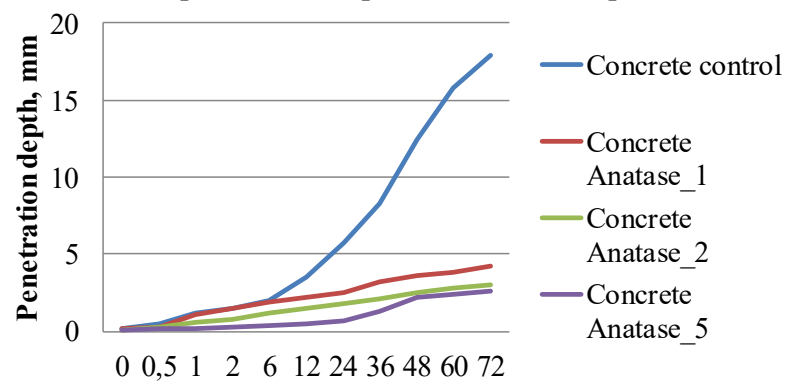

Fig. 2. The penetration depth of chlorides in concrete samples, with an exposure of $0-72$ hours

In previous experiments, it is proved that the introduction of a surfactant into a concrete mixture changes its thermal properties. Determination of technical characteristics, such as sample permeability, is presented in Fig. 3.

\section{Chloride penetration depth in concrete samples}

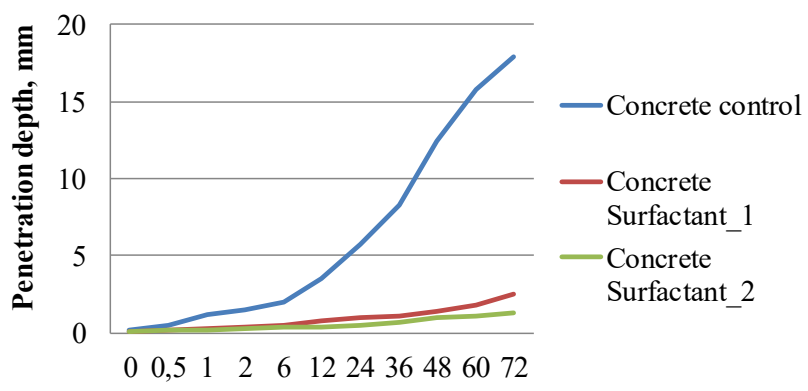

Fig. 3. The penetration depth of chlorides into concrete samples, with an exposure of $0-72$ hours

Surfactant (alkyl trimethylamine chloride) in experimental samples is used as a binder, based on its ability to form a nanofilm around concrete crystals when mixing concrete mass. A decrease in the permeability of the studied samples for chlorides is associated with an increase in the density of the sample.

According to the research conducted by scientists, the fact of the destruction of the concrete microstructure over time has been proved. Changes in the permeability of concrete samples of different ages are presented in Fig. 4.

\section{Chloride penetration depth in concrete samples}

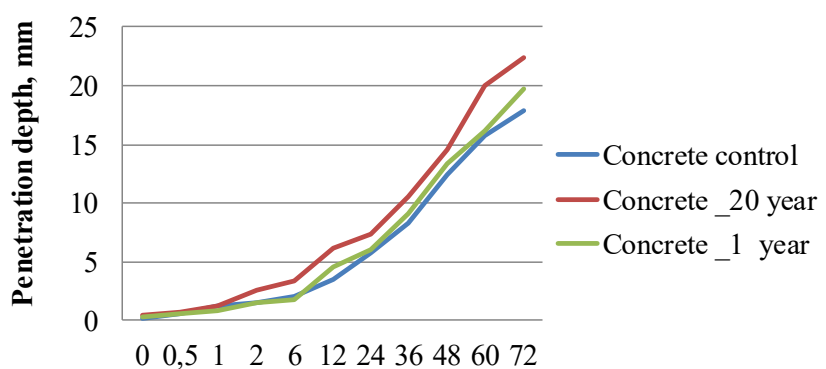

Fig. 4. The penetration depth of chlorides in concrete samples, with an exposure of 0-72 hours

Compared with control samples of 28 days of hardening, concrete with a life of 1 year and 20 years has a penetration depth for chlorides with an exposure of 72 hours of 22.4-19.8 mm. For concrete mixtures without additives, $0 \%$ penetration depth is $17.9 \mathrm{~mm}$.

The study of the properties of concrete with additives: nanocrystalline, small crystalline and binders (surfactants) for permeability and TPD-MS confirm their effectiveness. 


\section{2. Results of temperature programmed mass spectrometry (TPD-MS) of concrete} samples

Using the TPD-MS method to predict the direction and intensity of the effect of finely dispersed additives and surfactants on the fracture temperature of concrete samples (Fig. 5-7).

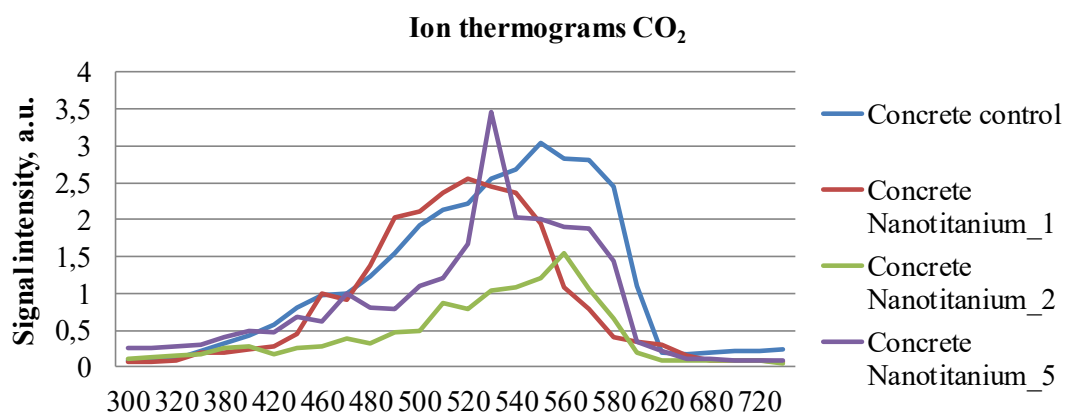

Fig. 5. Thermograms of $\mathrm{CO}_{2}$ emission/elimination $(\mathrm{m} / \mathrm{z}=44)$ by thermal decomposition of a sample

Fig. 5 shows the thermograms of fracture of concrete samples with the addition of $\mathrm{TiO}_{2}$ nanotitanium. The time and temperature of decomposition of the samples are recorded depending on the release of carbon monoxide $\mathrm{CO}$ and carbon dioxide $\mathrm{CO}_{2}$, as well as the evaporation of water molecules. The stronger the concrete sample, the less time and temperature of heating the sample at which it loses water and carbon monoxide. According to these data, thermograms are built. Concrete enriched with nanotitanium of 1-2\% concentration begins to emit carbon monoxide at a temperature of $520^{\circ} \mathrm{C}$. The maximum clearly defined intense peak of heating a concrete sample with the addition of $5 \%$ nanotitanium is $520-530{ }^{\circ} \mathrm{C}$. However, in comparison with other samples, it quickly heats up and cools, its peak decreases almost immediately. At temperatures from 420 to $520^{\circ} \mathrm{C}$, peaks are observed when heating experimental concrete samples due to dehydroxylation of concrete, combustion of organic substances and decomposition reaction.

At the same time, a control sample of concrete begins to emit carbon dioxide at temperatures starting from $550{ }^{\circ} \mathrm{C}$, which is caused by a looser structure. The content of nanocrystalline aggregates in the concrete leads to a decrease in the temperature of $\mathrm{CO}_{2}$ emission - the curve tends to the left, to lower temperatures. The control sample contains only coarse-grained additives, which take longer to heat up, the porosity of the sample is higher, and accordingly, the water molecules contained in micropores evaporate longer. The detail investigation of given in the Fig. $\mathbf{5}$ curves of the dependences of the yield of $\mathrm{CO}$ and $\mathrm{CO}_{2}$ from the samples on temperature reflect a pronounced tendency to shift the maximum yield of gaseous substances in the direction of increase in the heating temperature depending on the presence of impurities in the sample. Based on the obtained results, it can be concluded that concrete samples containing nanotitanium in their composition had a higher density compared to the control ones.

Fig. 6 shows a thermogram of heating concrete samples with the addition of anatase titanium with a particle size of 3-5 microns.

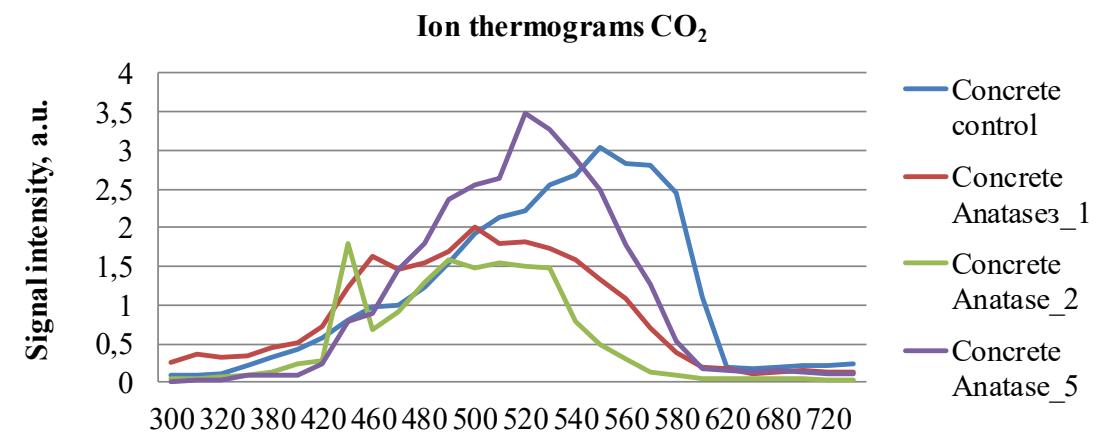

Fig. 6. Thermograms of $\mathrm{CO}_{2}$ emission/elimination $(\mathrm{m} / \mathrm{z}=44)$ by thermal decomposition of a sample 
The heating range of samples of $1-2 \%$ anatase is in the range $420-520{ }^{\circ} \mathrm{C}$. Concrete with $5 \%$ anatase does not give a clear peak at $520{ }^{\circ} \mathrm{C}$. The thermogram of the control sample is in a higher temperature range of $560-580{ }^{\circ} \mathrm{C}$, the process is endothermic due to the dissociation of carbonates. In control samples, organic substances are burned, water is removed due to dehydroxylation and decomposition of carbonates, but at higher temperatures, in comparison with experimental ones.

In the following experimental samples, alkyl trimethylamine chloride, which contains a quaternary ammonium salt, a nonionic surfactant, is used as a binder (Fig. 7).

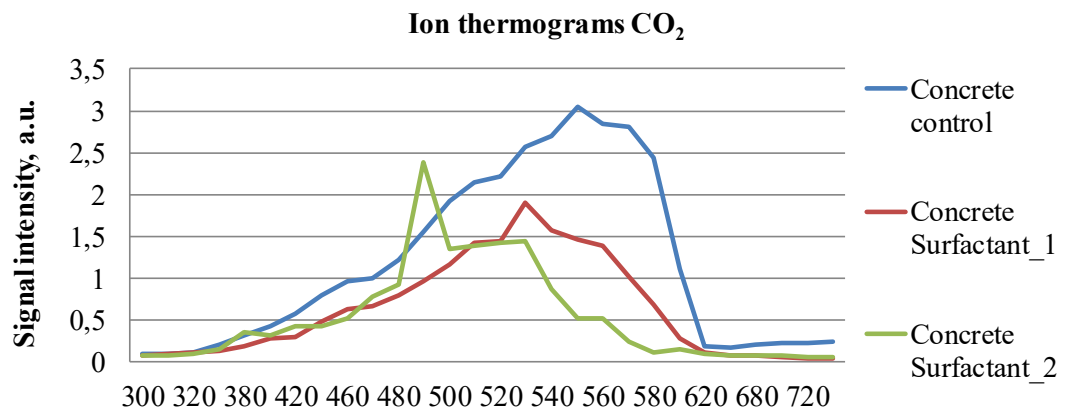

Fig. 7. Thermograms of $\mathrm{CO}_{2}$ emission/elimination $(\mathrm{m} / \mathrm{z}=44)$ by thermal decomposition of a sample

As a result of the experiment, it is found that the incandescent temperature of samples with the addition of a surfactant of $2 \%$ is $490{ }^{\circ} \mathrm{C}$, and that of a surfactant of $1 \%$ is $520^{\circ} \mathrm{C}$. The moment of maximum incandescence, at which concrete samples lose carbon monoxide and dioxide, as well as mass spectrometer. An increase in the percentage of surfactant to concrete reduces the time and temperature of heating the sample. It is possible that surfactants fill most of the caverns and spaces in concrete. As a result, the test samples have a smaller diameter of the caverns, in comparison with the control.

In the process of applying the TPD-MS method in the temperature range $300-720^{\circ} \mathrm{C}$, hydrated products are dehydrated and weight was lost in concrete samples (Table 3).

\section{Table 3}

Results of weight loss by concrete samples during glowing at a temperature of $300-720{ }^{\circ} \mathrm{C}$

\begin{tabular}{ccccc}
\hline Samples & \% & $\begin{array}{c}\text { The initial weight of } \\
\text { the sample, } \mathbf{m g}\end{array}$ & $\begin{array}{c}\text { The final weight of } \\
\text { the sample, } \mathbf{~ m g}\end{array}$ & Weight loss, \% \\
\hline & 0 & 3,0 & 2,52 & 16,0 \\
$\mathrm{TiO}_{2}$ & 1 & 3,0 & 2,67 & 11,0 \\
nanotitanium & 2 & 3,0 & 2,73 & 9,0 \\
& 5 & 3,0 & 2,75 & 11,6 \\
$\mathrm{TiO}_{2}$ & 1 & 3,0 & 2,65 & 10,0 \\
Titanium anatase & 2 & 3,0 & 2,70 & 8,7 \\
& 5 & 3,0 & 2,74 & 10,6 \\
Surfactant & 1 & 3,0 & 2,68 & 8,0
\end{tabular}

The results show that after concrete is heated, water and other substances evaporate, which leads to weight loss of the samples. An increase in weight loss is diametrically opposite to the amount of $\mathrm{TiO}_{2}$ nanoparticles introduced into concrete up to $5 \%$ and surfactant up to $2 \%$. Maximum weight loss occurs in control samples that contain more water and other hydration products. 
An increase in the percentage of $\mathrm{TiO}_{2}$ and titanium nanoparticles in anatase form up to $5 \%$; surfactants up to $2 \%$ in concrete mixtures accelerate peak load times and remove heat. Based on the results obtained, it can be concluded that the experimental concrete samples had a higher density compared to the control.

\section{Discussion}

The use of concrete in construction provides reliable and durable operation of the structure, but for such conditions of operation of the object, it is necessary to obtain concrete with the necessary characteristics [16].

The results of testing the physicomechanical properties of concrete samples on the 7th, 28th, and 90th day of hardening with the addition of titanium dioxide nanoparticles $($ nanoTiO 2 ) and finely dispersed titanium dioxide in anatase crystalline form (anatazTiO $\mathrm{C}_{2}$ ) at 1 and $2 \%$ concentration show a significant increase in compressive strength. The strength of concrete samples decreases when the additive is increased to $5 \%$.

A decrease in the penetration depth of chlorides occurs due to a decrease in water absorption in concrete due to the introduction of additives that caused compaction of the samples. When a nanodispersed additive of titanium dioxide is introduced into concrete from $1 \%$ to $5 \%$, the chloride penetration depth decreased to $3.0 \mathrm{~mm}$, respectively. The addition of a small-crystalline anatase titanium additive to concrete in the range of $1 \%$ to $5 \%$, the depth of absorption of a $3 \% \mathrm{NaCl}$ solution stopped at around 2.6-4.2 $\mathrm{mm}$. So, thanks to additives, the formed structure has discontinuous pores and significantly reduces the penetration of chlorides into the samples.

The authors of [17] give another point of view on the mechanism of the influence of mineral fillers on the strength of cement concrete. Its essence lies in the fact that finely dispersed fillers affect the differential porosity of cement stone, characterized by the different sizes of pores and the heterogeneity of their distribution in volume.

Along with this, the researchers [18] argue that with a high degree of filling, after reaching its maximum, concrete strength decreases despite a continued decrease in the porosity of cement stone, due to a deterioration in the adhesion of the filled cement stone to the aggregate.

Concrete with additives is made according to the requirements for production, taking into account the temperature, humidity and exposure to hardening.

However, during operation in livestock buildings under the influence of constant humidity, concentrated acids and alkalis, destruction of the concrete surface may occur, despite the added additives. Also, when using concrete for road surfaces, temperature extremes, the use of salt and the uneven load of heavy equipment can cause cracking. Therefore, in conditions of increasing loads on concrete, it is necessary to take into account the decrease in the expected service life.

The application of the method of temperature-programmed desorption mass spectrometry (TPD-MS) proves that an increase in the percentage of $\mathrm{TiO}_{2}$ nanoparticles to $5 \%$ in concrete mixtures accelerates the heating of samples at lower temperatures, which indicates an increase in strength.

According to studies on the thermogram of a Portland cement stone of normal hardening, three main endothermic effects are identified, caused by the removal of adsorption water from the gel-like hydration products and crystalline hydrated water from calcium hydrosulfoaluminate (up to $300{ }^{\circ} \mathrm{C}$ ), as well as the dehydration of Portlandite $-\mathrm{Ca}(\mathrm{OH})_{2}\left(300-580{ }^{\circ} \mathrm{C}\right)$ and dissociation of $\mathrm{CaCO}_{3}\left(580-720^{\circ} \mathrm{C}\right)$.

The TPD-MS method is for the most part qualitative and can't provide absolutely accurate digital data. The whole reason is the chemical differences between concretes and the low content of carbonates in them (carbon monoxide $\mathrm{CO}$ and carbon dioxide $\mathrm{CO}_{2}$ ). Therefore, comparing concrete with a different composition and interpreting the results obtained is a complex process. All tested concrete samples are equal to the control. Peaks of emission of carbon ions are taken for reliable, provided that they exceed the background by $15-20 \%$.

After concrete is heated, water and other substances evaporate, which leads to weight loss of the samples. Regular concrete loses after glowing $16 \%$ of its original weight. With an increase in the concentration of introduced $\mathrm{TiO}_{2}$ nanoparticles into concrete up to $5 \%$ and surfactant 
up to $2 \%$, weight loss decreases almost twice. Conventional concrete contains more hydration products that evaporate during heating, and the sample significantly loses its original weight.

Thus, the use of additives based on titanium dioxide nanoparticles (nanoTiO $)_{2}$ ), finely dispersed anatase crystalline titanium dioxide $\left(\right.$ anatazTiO ${ }_{2}$ ), surfactants (alkyl trimethylamine chloride) can increase the density of the structure, and, as a result, the strength, durability and resistance of concrete in aggressive operating conditions.

It should be noted that adsorbing on cement grains and the surface of hydrated new formations, surfactants manifest themselves not only as plasticizers, but also as hardening inhibitors.

Slowing down of hardening and structure formation in the presence of most surfactant additives occurs as a result of a decrease in water diffusion through the adsorption shell. The rate of cement hydration in the presence of a surfactant depends on the chemical composition of the additive and its concentration.

It is also known that most organic additives, ensuring the achievement of high rheological and technological effects, slow down the hardening process of cement and monomineral systems for a certain time. However, the dispersing effect of organic additives helps to accelerate hydration and hardening, since disaggregated binder particles begin to actively interact with the liquid phase, thereby accelerating the hardening kinetics and, in many cases, providing a significant increase in strength in the later stages. Moreover, for cement systems filled with finely dispersed mineral additives, there is no retardation of hardening, since the nature, and, consequently, the mechanism of the activating effect of mineral additives is fundamentally different from the mechanism of action of organic additives [19].

The need to search for new additives is determined by the selective nature of their modifying effect, which depends not only on the chemical composition of the additives, but also on the chemical and mineralogical composition of cement, and the fineness of its grinding. The magnitude of the modifying effect of many additives also depends on the specific consumption of cement in the concrete mix, the content and type of mineral additives, the water-cement ratio and the heat treatment regimes.

In modern construction, concrete is one of the main structural materials, the production level of which is constantly increasing [20]. Modern research methods and the development of advanced technologies, including nanotechnology, allow to directionally affect the structure and properties of cement mortars and concretes and obtain materials with high technological and physico-technical parameters.

The prospect of further research is to conduct temperature programmed mass spectrometry (TPD-MS) and to study the permeability of concrete samples with microadditives after a year or more, in comparison with existing samples in real time.

\section{Conclusions}

It is experimentally proved that concrete samples containing up to $5 \%$ nanotitanium and anatase titanium show an increase in compression density compared to control samples by 23.2 and $21.7 \%$, respectively. Concrete samples containing 1 and $2 \%$ surfactant concentration also had a higher compression density of $18.9 \%$ and $21.7 \%$, respectively.

The use of temperature-programmed desorption mass spectrometry (TPD-MS) has proved that increasing the percentage of $\mathrm{TiO}_{2}$ nanoparticles to $5 \%$ in concrete mixtures accelerates the heating time at lower temperatures and proves the increase in the strength of experimental samples.

The addition of titanium dioxide $\left(\right.$ nanoTiO $\left._{2}\right)$, finely dispersed anatase crystalline titanium dioxide $\left(\right.$ anatazTiO ${ }_{2}$ ) and surfactants reduces the permeability of concrete samples for chlorine ions by up to $10 \%$.

\section{References}

[1] Nazari, A., Riahi, S. (2010). The effect of $\mathrm{TiO}_{2}$ nanoparticles on water permeability and thermal and mechanical properties of high strength self-compacting concrete. Materials Science and Engineering: A, 528 (2), 756-763. doi: https://doi.org/10.1016/ j.msea.2010.09.074 
[2] Aravind, R., Devasena, M., Sreevidya, V., Vadivel, M. (2016). Dispersion characteristics and flexural behavior of concrete using nano titanium dioxide. International Journal of Earth Sciences and Engineering, 9 (3), $443-447$.

[3] Fattah, K., Tamimi, A., Alkadi, A., Afaneh, M., Awada, M., Khalaf, A. (2019). Self-Cleansing Cement Matrix using Nano Titanium Dioxide. International Journal of Advances in Mechanical and Civil Engineering (IJAMCE), 6 (1), 37-41.

[4] Nazari, A., Riahi, S., Riahi, S., Shamekhi, S. F., Khademnoand, A. (2010). An investigation on the Strength and workability of cement based concrete performance by using $\mathrm{ZrO}_{2}$ nanoparticles. Journal of American Science, 6 (4), $29-33$.

[5] Prusty, J. K., Patro, S. K., Basarkar, S. S. (2016). Concrete using agro-waste as fine aggregate for sustainable built environment - A review. International Journal of Sustainable Built Environment, 5 (2), 312-333. doi: https://doi.org/10.1016/ j.ijsbe.2016.06.003

[6] Okojie, L. O. (2014). Cement Production and Sustainable Rural Farming Livelihood in Nigeria: Striking a Sensible Balance Through Environmental Legislation and Enforcement. European Journal of Sustainable Development, 3 (3), $250-262$. doi: https://doi.org/10.14207/ejsd.2014.v3n3p251

[7] Gelardi, G., Mantellato, S., Marchon, D., Palacios, M., Eberhardt, A. B., Flatt, R. J. (2016). Chemistry of chemical admixtures. Science and Technology of Concrete Admixtures, 149-218. doi: https://doi.org/10.1016/b978-0-08-100693-1.00009-6

[8] Farzad, S. (2012). Effects of $\mathrm{TiO}_{2}$ nanoparticles on increasing split tensile strength of limestone aggregate-based concrete. Journal of American Science, 8 (2), 715-718. Available at: http://www.jofamericanscience.org/journals/am-sci/am0802/ 100_8651am0802_715_718.pdf

[9] Hunashyal, A. M., Tippa, S. V., Quadri, S. S., Banapurmath, N. R. (2011). Experimental Investigation on Effect of Carbon Nanotubes and Carbon Fibres on the Behavior of Plain Cement Mortar Composite Round Bars under Direct Tension. ISRN Nanotechnology, 2011, 1-6. doi: https://doi.org/10.5402/2011/856849

[10] Visser, J. H. M. (2014). Influence of the carbon dioxide concentration on the resistance to carbonation of concrete. Construction and Building Materials, 67, 8-13. doi: https://doi.org/10.1016/j.conbuildmat.2013.11.005

[11] Marangu, J. M., Thiong'o, J. K., Wachira, J. M. (2019). Review of Carbonation Resistance in Hydrated Cement Based Materials. Journal of Chemistry, 2019, 1-6. doi: https://doi.org/10.1155/2019/8489671

[12] Smykatz-Kloss, W. (1974). Differential Thermal Analysis. Application and Results in Mineralogy. Minerals and Rocks. Springer. doi: https://doi.org/10.1007/978-3-642-65951-5

[13] DSTU B B.2.7-224:2009 (2010). Building materials. Concrete strength control rules. Minregionstroy of Ukraine. Kyiv, 23.

[14] Methodical instructions for determining the sensitivity of microorganisms to antimicrobials by the method of diffusion into agar using standard disks with antibiotics (approved by the SCCM Scientific Council of Ukraine from 20.12.2007).

[15] Bertron, A. (2014). Understanding interactions between cementitious materials and microorganisms: a key to sustainable and safe concrete structures in various contexts. Materials and Structures, 47 (11), 1787-1806. doi: https://oi.org/10.1617/s11527014-0433-1

[16] Shekari, A. H., Razzaghi, M. S. (2011). Influence of Nano Particles on Durability and Mechanical Properties of High Performance Concrete. Procedia Engineering, 14, 3036-3041. doi: https://doi.org/10.1016/j.proeng.2011.07.382

[17] Ilyina, L. V., Khakimullin, S. A., Sidorkin, D. A. (2017). Influence of dispersed mineral additives on the strength of finegrained concrete. Fundamental research, 4 (1), 34-38.

[18] Nguyen, D. V. Q., Aleksandrova, O. V., Bazhenov, Y. M. (2019). Effect of quartz powder and mineral admixtures on the properties of high-performance concrete. Vestnik MGSU, 1, 102-117. doi: https://doi.org/10.22227/1997-0935.2019.1.102-117

[19] Burenina, O. N., Davydova, N. N., Andreeva, A. V., Davaasenga, S. S., Savvinova, M. E. (2015). Investigation of the effect of complex mineral modifying additives, including nano-additives, on the properties of fine concrete. Current issues of technical Sciences: materials of the III international conference. science. Conf. Perm: Zebra, 101-104.

[20] Kosmatka, S. H., Wilson, M. L. (2011). Design and Control of Concrete Mixtures, EB001. Illinois, 460.

Received date 03.02.2020

Accepted date 23.03.2020

Published date 31.03.2020
(C) The Author(s) 2020

This is an open access article under the CC BY license (http://creativecommons.org/licenses/by/4.0). 